\title{
Genomic distribution of AFLP markers relative to gene locations for different eukaryotic species
}

\author{
Armando Caballero*, María Jesús García-Pereira and Humberto Quesada
}

\begin{abstract}
Background: Amplified fragment length polymorphism (AFLP) markers are frequently used for a wide range of studies, such as genome-wide mapping, population genetic diversity estimation, hybridization and introgression studies, phylogenetic analyses, and detection of signatures of selection. An important issue to be addressed for some of these fields is the distribution of the markers across the genome, particularly in relation to gene sequences.

Results: Using in-silico restriction fragment analysis of the genomes of nine eukaryotic species we characterise the distribution of AFLP fragments across the genome and, particularly, in relation to gene locations. First, we identify the physical position of markers across the chromosomes of all species. An observed accumulation of fragments around (peri) centromeric regions in some species is produced by repeated sequences, and this accumulation disappears when AFLP bands rather than fragments are considered. Second, we calculate the percentage of AFLP markers positioned within gene sequences. For the typical EcoRI/Msel enzyme pair, this ranges between 28 and $87 \%$ and is usually larger than that expected by chance because of the higher GC content of gene sequences relative to intergenic ones. In agreement with this, the use of enzyme pairs with GC-rich restriction sites substantially increases the above percentages. For example, using the enzyme system Sacl/Hpall, 86\% of AFLP markers are located within gene sequences in A. thaliana, and $100 \%$ of markers in Plasmodium falciparun. We further find that for a typical trait controlled by 50 genes of average size, if 1000 AFLPs are used in a study, the number of those within $1 \mathrm{~kb}$ distance from any of the genes would be only about $1-2$, and only about $50 \%$ of the genes would have markers within that distance.

Conclusions: The high coverage of AFLP markers across the genomes and the high proportion of markers within or close to gene sequences make them suitable for genome scans and detecting large islands of differentiation in the genome. However, for specific traits, the percentage of AFLP markers close to genes can be rather small. Therefore, genome scans directed towards the search of markers closely linked to selected loci can be a difficult task in many instances.
\end{abstract}

Keywords: AFLP, Candidate genes, Genome scans, Genomic signature, Restriction-site markers

\section{Background}

Amplified fragment length polymorphisms (AFLP; [1]) are extensively used in evolutionary, population genetics and conservation studies on plants, animals and microorganisms [2,3]. Applications of these markers are particularly useful in non-model species for which no prior DNA sequence is available, and where other alternative wide-genome markers, such as SNPs, are difficult to obtain. AFLP markers are also very useful because of their low cost relative to other markers [4]. Thus, AFLP

\footnotetext{
*Correspondence: armando@uvigo.es

Departamento de Bioquímica, Genética e Inmunología, Facultad de Biología, Universidade de Vigo, 36310, Vigo, Spain
}

markers have been used for a wide range of objectives, such as genome-wide mapping (e.g. [5]), population genetic diversity estimation, hybridization and introgression studies (e.g. [6-8]), phylogenetic analyses (e.g. [9-11]) and detection of signatures of selection (e.g. [12-17]). More recently, restriction site associated DNA markers (RAD; $[18,19]$ ) have been suggested as an alternative tool for some of the above objectives, although important problems also affect this type of marker [20,21].

Several concerns regarding the application of AFLP markers have been addressed and discussed in the recent years. One is the possible lack of homology due to fragment size homoplasy [16,22-25]. Homoplasy may 
produce biases in the estimates of population genetic parameters $[22,26]$, in the efficiency of the methods to detect loci under positive selection in genome-wide scans [26], and in phylogenetic reconstruction (e.g. [9,27-30]). However, the use of homoplasy-corrected estimators of genetic similarity from AFLP bands [31] and the use of a restricted number of markers per primer combination $[1,2,28]$ allows for a minimization of the impact of homoplasy on the multiple applications of AFLP markers. Other concerns regarding AFLP markers are the difficulties in isolating and characterising AFLP loci [32] and the possible problems due to insufficient fragment mobility resolution or an incorrect scoring of bands [33]. Some of these problems are currently addressed by new scoring method proposals [34-36] or quantitative genetic approaches [7].

A further issue to be addressed in the use of AFLP markers, particularly regarding their applications in QTL mapping and detection of signatures of selection, is the distribution of the markers across the genome. Although AFLP markers are assumed to offer a good genomic coverage, it has been reported that they are frequently clustered around centromeric regions (e.g. [37-39]). In addition, several studies recognize the presence of overand under-representation of short oligonucleotides in DNA sequences that can be regarded as a genomic signature of the species (e.g. [40-42]) and could affect the distribution of AFLP markers across the genome. In fact, neither the distribution of AFLP fragment lengths nor the distribution of AFLP positions across the genome are random $[23,24]$. Finally, it has been repeatedly seen that gene concentration increases from GC-poor to GCrich regions of the eukaryotic genomes (e.g. [43,44]). Thus the ability of restriction-site markers to be localised in gene or intergene sequences should depend on the restriction enzymes used.

In QTL mapping studies as well as in analyses of detection of loci under selection in genome-wide scans, hundreds or thousands of markers are used with the aim of finding markers associated to the loci of interest. The association is made through the observation of a correlation between markers and the trait of interest in the first case, or the observation of a high level of differentiation among populations for the markers in the second. Many of these studies are carried out with restriction site markers, particularly AFLPs, and it is relevant to know whether the distribution of these markers is suitable for such studies. For example, recent extensive genome scans indicate that genetic differentiation of markers attached to selected regions does not extend beyond about $1-5 \mathrm{~kb}$ around the adaptive loci [45]. It is thus important to have a priori predictions of the upper number of markers expected to be within or close to the genes of interest.
In this paper we focus on the above issues analysing whole genome sequences and data on gene positions on the genome from different eukaryotic species. We first identify the physical position of AFLP fragments across the chromosomes of nine sequenced eukaryotic species to check their genome coverage. Second we compute the physical distance between AFLP markers and their nearest genes in order to see the proportion of markers physically associated to genes. Finally, we illustrate the relative position of AFLP markers with respect to specific sets of genes controlling a particular trait of interest.

\section{Results}

\section{Distribution of AFLP markers across the genome}

We first focus on the Arabidopsis thaliana genome, as a number of in-silico studies have been carried out previously on this species. The distribution of the number of AFLP fragments (EcoRI/MseI) and the number of genes across the different chromosomes are shown in nonoverlapping windows of $200 \mathrm{~kb}$ in Figure 1A. It is apparent that a certain accumulation of AFLP fragments are located around or in the centromeric regions, particularly for chromosomes 3 and 5. The reason for these increases in the number of fragments can be ascribed to the higher GC content attached to these genomic areas (Figure 1B). Indeed, although the number of MseI sites is lower in these regions than in others (Figure 2A), the number of EcoRI sites they contain is drastically increased (Figure 2B), leading to an increase in the number of AFLP fragments. Nevertheless, the excess of AFLP fragments around the centromeric regions, virtually disappears when AFLP bands rather than fragments are considered in the analysis (Figure 3). The reason is that in the centromeric regions repeated sequences which produce particular fragments of the same size occur and can be expected to collide in the same electrophoretic band. In order to check this explanation, we looked in detail at the centromeric regions of chromosomes 3 and 5 as defined by The Arabidopsis Genome Initiative [46]. We found, for example, that an AFLP fragment sequence of $104 \mathrm{bp}$ in the centromeric region of chromosome 3 repeated 50 times. In chromosome 5 there was an AFLP fragment sequence of $117 \mathrm{bp}$ repeated 63 times and one of 116 bp repeated 9 times.

The distribution of AFLP bands and genes for the other analyzed species are given in the Additional file 1: Figures S1-S8. In general, no regions with extreme accumulation of AFLP bands were observed.

\section{Distance between AFLP markers and genes for the whole genome}

The first row of Table 1 shows the total genome length available and analyzed for each of the species. The percentage of un-sequenced nucleotides was relatively small 

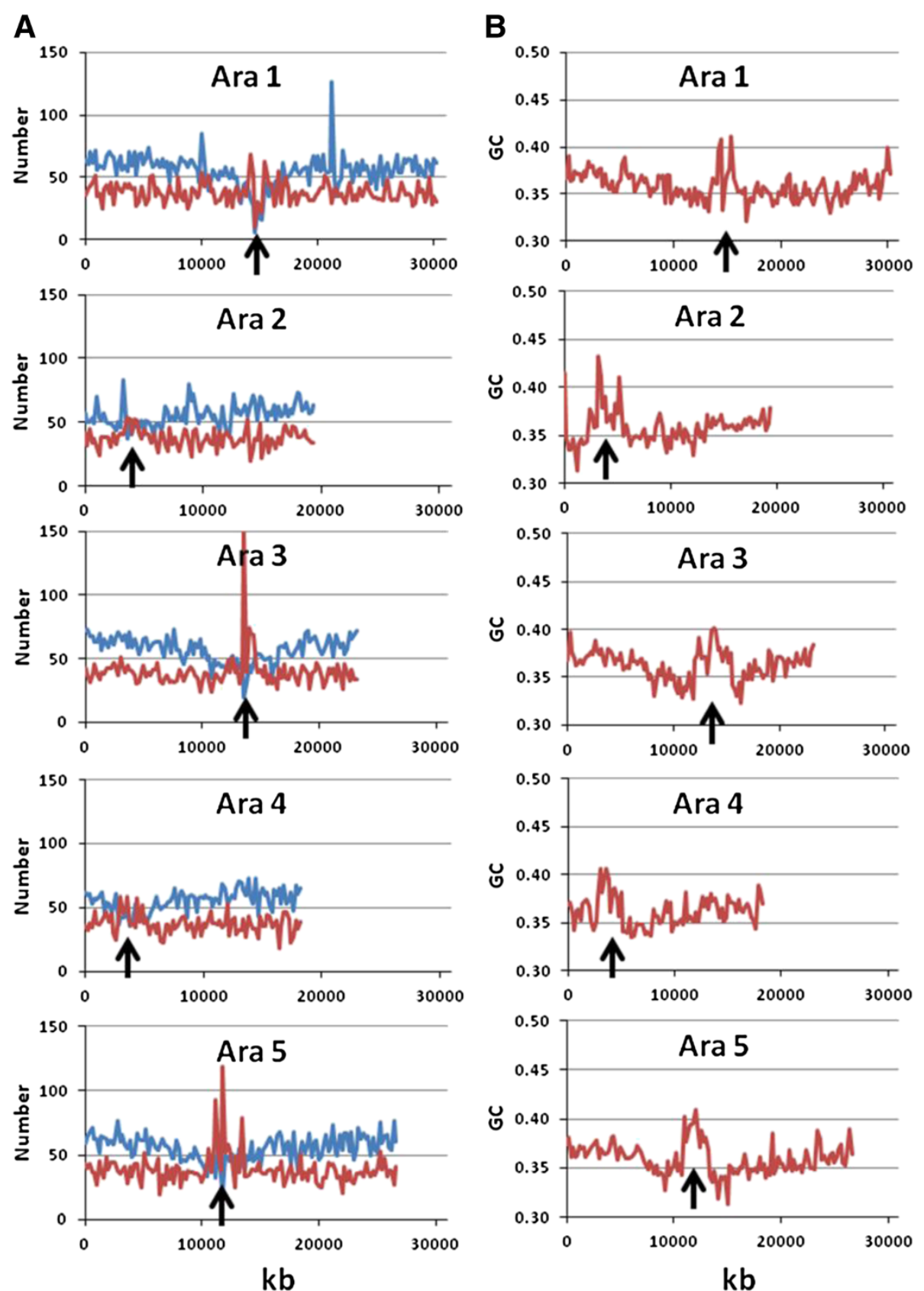

Figure 1 Distribution of the number of AFLP fragments, number of genes, and average GC content, across the different chromosomes of Arabidopsis thaliana, shown in non-overlapping windows of $\mathbf{2 0 0} \mathbf{~ k b}$. (A) Number of AFLP fragments (EcoRI/Msel) in red, number of genes in blue. (B) Average GC content. The approximate location of the centromeric regions is marked with an arrow.

in all cases $(7.79 \%$ in Homo, $2.63 \%$ in Oryza, $2.36 \%$ in Anopheles, $0.08 \%$ in Drosophila, $0.16 \%$ in Arabidopsis, $0 \%$ in Caenorhabditis, $0.004 \%$ in Plasmodium, $0.003 \%$ in Schizosaccharomyces, and 0\% in Saccharomyces). The results presented below are not affected by these unsequenced nucleotides because AFLPs, gene locations and their distances obviously refer only to sequenced areas, with un-sequenced nucleotides generally being clustered in large regions. The second and third rows show the GC content for each species for gene and intergene sequences. Note that the GC\% is consistently larger for the former than for the latter. The next two rows show the total number of genes and the gene length mean and its standard deviation.

The next block of rows shows results for AFLP fragments cut by enzymes EcoRI/MseI. Note that the total 

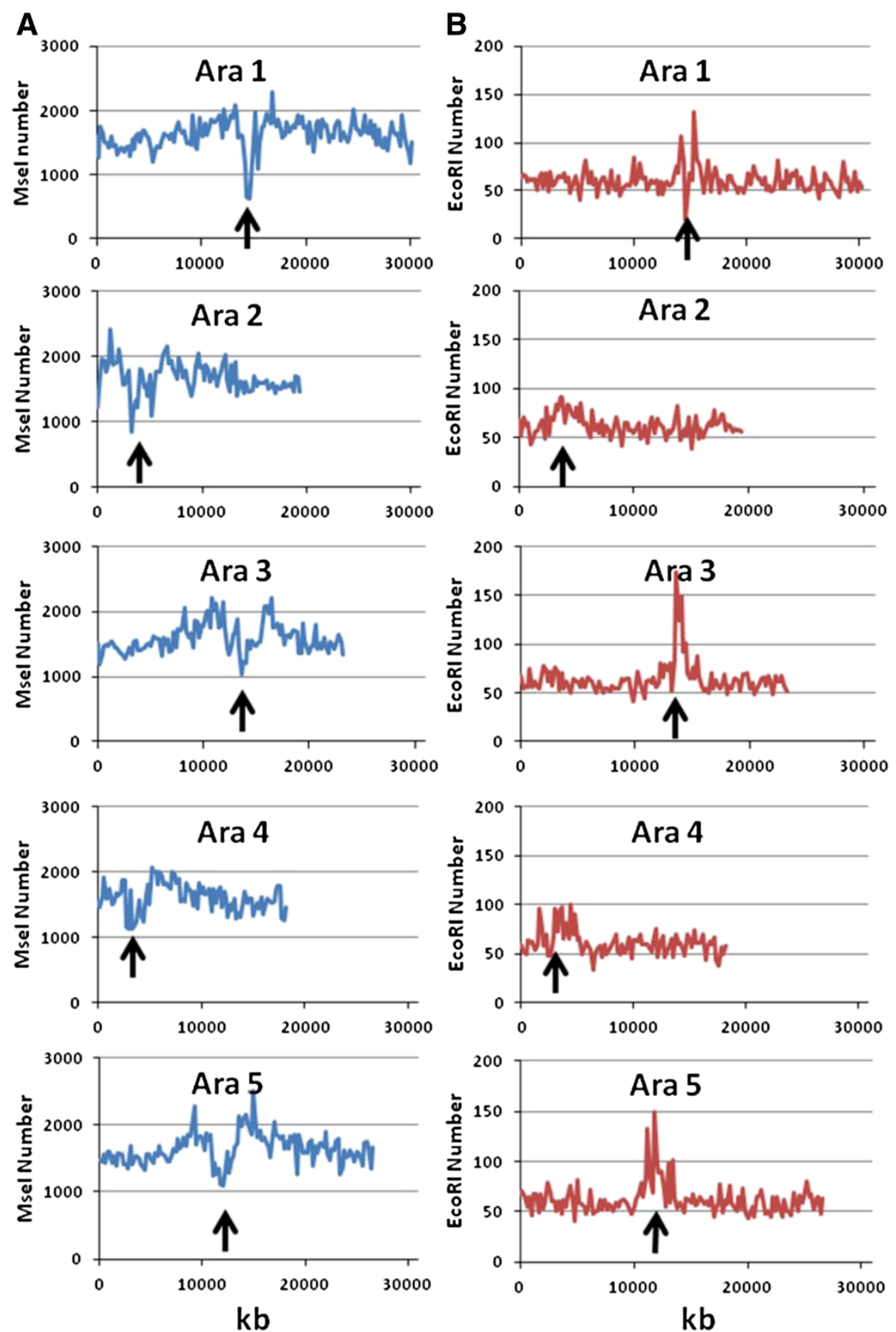

Figure 2 Distribution of the number of Msel (A) and EcoRI (B) cutting sites across the different chromosomes of Arabidopsis thaliana, shown in non-overlapping windows of $\mathbf{2 0 0} \mathbf{~ k b}$. The approximate location of the centromeric regions is marked with an arrow.

number of AFLP fragments is generally larger than the number of genes for species with large genome sizes, but the mean distance between AFLPs is relatively uniform across all species, with most values ranging between about 4 and $8 \mathrm{~kb}$.

Next, the table presents the percentage of AFLP fragments positioned at a given physical distance from the closest gene. AFLP markers at a $0 \mathrm{~kb}$ distance from genes refer to those within the gene sequence or overlapping it. The expected value of this percentage if AFLP fragments were randomly positioned in the genome is shown in parenthesis. This expectation is simply calculated as the percentage of the sequenced genome covered by all gene sequences. For 6 out of 9 species 

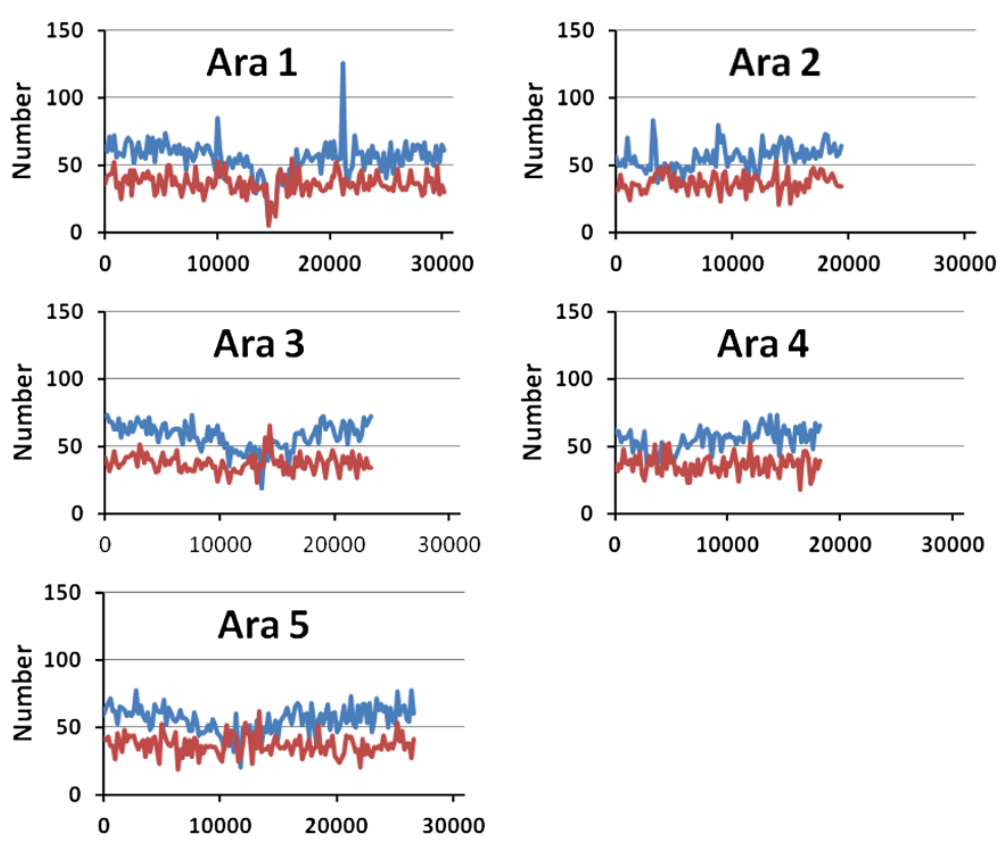

Figure 3 Distribution of the number of AFLP bands (EcoRI/Msel) (in red) and the number of genes (in blue) across the different chromosomes of Arabidopsis thaliana, shown in non-overlapping windows of $200 \mathrm{~kb}$.

the observed percentage is larger than the random expectation. AFLP markers at $1 \mathrm{~kb}$ distance from genes include also those at $0 \mathrm{~kb}$ distance, etc.

The next group of rows in Table 1 shows the percentage of genes with AFLP fragments at a given distance. The percentage of genes with AFLPs at $0 \mathrm{~kb}$ distance indicates those genes with at least one AFLP fragment inside the gene sequence. The expectation of this value, given in parenthesis, is the Poisson expectation with the observed mean number of AFLP fragments per locus. For all species the observed percentage is lower than the expected value. The percentage of genes with zero, one, two, etc. AFLP fragments inside gene sequences is given in Figure 4. The discrepancy between observed and expected values can be ascribed to the fact that the poisson expectation assumes equal gene length sequence for all genes, a clearly untrue assumption, particularly for the human genome. Note that the percentage of genes having AFLP fragments below $1 \mathrm{~kb}$ distance is around $50-60 \%$ for most of the species (Table 1).

All the above results refer to AFLP fragments using the typical tandem EcoRI/MseI. The four last rows of Table 1 show some results for tandems with a balanced AT/GC (BsmI/TaqI) or a GC biased (SacI/HpaII) recognition sequence. The number of AFLP fragments is normally decreased (although, for some species, increased) with the GC content of the restriction sites $(2 / 10 \mathrm{GC}$ nucleotides for EcoRI/MseI, 5/10 for BsmI/TaqI, and 8/10 GC for SacI/HpaII). Note that the percentage of
AFLP fragments inside gene sequences is increased with an increase of the GC content of the restriction sites for all cases except for Oryza. In addition, the use of selective G/C nucleotides slightly increases this percentage. For example, using the pair EcoRI/MseI with one selective nucleotide ( $\mathrm{G}$ or $\mathrm{C}$ ) at each extreme of the fragment, the percentage of AFLP fragments inside gene sequences increases from $27 \%$ (no selective nucleotides) to 29\% (G or C selective nucleotides) for Anopheles, and from $65 \%$ to $66 \%$ in Caenorhabditis. Using the pair SacI/HpaII the corresponding increases were from 39\% to $46 \%$, and from $75 \%$ to $77 \%$, respectively.

\section{Examples of distances between AFLP markers and genes for specific traits}

In order to illustrate the availability of AFLP markers close to a specific set of genes, we considered three examples of candidate genes in three of the species analysed above (Table 2). The distribution among chromosomes of 42 candidate genes for Aluminium tolerance in Oryza sativa is $7,5,5,3,4,2,3,0,2,5,3$ and 3 for chromosomes 1 to 12, respectively; that of 50 candidate genes for flowering time in Arabidopsis thaliana is 9, 9, 7, 12 and 13 for chromosomes 1 to 5 , respectively; and that for 89 candidate genes for developmental time in Drosophila melanogaster is $12,16,21,15$ and 25 for chromosomes $2 \mathrm{~L}, 2 \mathrm{R}, 3 \mathrm{~L}, 3 \mathrm{R}$ and $\mathrm{X}$, respectively.

The average gene length of the Drosophila candidate genes for developmental time is particularly large (30.4 kb; 
Table 1 In-silico analysis of whole genome sequences from 9 eukaryotic species (Homo sapiens, Oryza sativa, Anopheles gambiae, Drosophila melanogaster, Arabidopsis thaliana, Caenorhabditis elegans, Plasmodium falciparum, Schizosaccharomyces pombe and Saccharomyces cerevisiae)

\begin{tabular}{|c|c|c|c|c|c|c|c|c|c|}
\hline & Homo & Oryza & Anoph. & Droso. & Arab. & Caeno. & Plasm. & Schizo. & Sacch. \\
\hline Genome size (Mb) & 3003 & 382 & 230 & 120 & 119 & 100 & 23 & 13 & 12 \\
\hline GC\% (gene sequences) & 0.419 & 0.446 & 0.473 & 0.437 & 0.393 & 0.364 & 0.227 & 0.388 & 0.396 \\
\hline GC\% (intergenic sequences) & 0.402 & 0.432 & 0.433 & 0.403 & 0.313 & 0.341 & 0.144 & 0.345 & 0.347 \\
\hline Number of genes & 36036 & 30295 & 12688 & 14604 & 33239 & 21175 & 5509 & 5060 & 6281 \\
\hline Mean (stand. dev.) gene length (kb) & $35.5(81.2)$ & $3.0(2.6)$ & $5.9(4.5)$ & $6.3(4.7)$ & $2.1(1.6)$ & $2.9(3.3)$ & $2.5(2.6)$ & $1.4(0.7)$ & $1.4(1.2)$ \\
\hline \multicolumn{10}{|l|}{ Enzymes EcoRI/Msel } \\
\hline Number of AFLPs & 459944 & 50437 & 28336 & 20767 & 22836 & 27345 & 2017 & 2748 & 2891 \\
\hline Mean distance between AFLPs (kb) & 6.7 & 7.4 & 8.0 & 5.7 & 5.1 & 3.5 & 11.2 & 4.4 & 4.1 \\
\hline \multicolumn{10}{|c|}{$\%$ AFLPs at a given distance from genes } \\
\hline $0 \mathrm{~kb}\left(E X P^{*}\right)$ & $41(43)$ & $29(25)$ & $28(32)$ & $63(63)$ & $67(59)$ & $65(59)$ & $79(59)$ & $71(60)$ & $87(73)$ \\
\hline $1 \mathrm{~kb}$ & 43 & 42 & 36 & 71 & 89 & 83 & 96 & 94 & 99 \\
\hline $10 \mathrm{~kb}$ & 53 & 80 & 64 & 92 & 99 & 100 & 100 & 99 & 100 \\
\hline \multicolumn{10}{|c|}{$\%$ Genes with AFLPs at a given distance } \\
\hline $0 \mathrm{~kb}\left(E X P^{* *}\right)$ & $48(99)$ & $33(38)$ & $27(46)$ & $35(59)$ & $34(37)$ & $47(57)$ & $23(25)$ & $31(32)$ & $31(33)$ \\
\hline $1 \mathrm{~kb}$ & 63 & 50 & 45 & 56 & 55 & 70 & 31 & 56 & 57 \\
\hline $10 \mathrm{~kb}$ & 92 & 95 & 93 & 96 & 98 & 100 & 85 & 100 & 99 \\
\hline \multicolumn{10}{|l|}{ Enzymes Bsml/Taql } \\
\hline Number of AFLPs & 101630 & 31357 & 35330 & 21155 & 10441 & 12518 & 464 & 1751 & 1475 \\
\hline$\%$ AFLPs at $0 \mathrm{~kb}$ from genes & 45 & 30 & 33 & 64 & 73 & 69 & 92 & 76 & 84 \\
\hline \multicolumn{10}{|l|}{ Enzymes Sacl/Hpall } \\
\hline Number of AFLPs & 131756 & 45330 & 17529 & 10234 & 6579 & 7098 & 19 & 406 & 467 \\
\hline$\%$ AFLPs at $0 \mathrm{~kb}$ from genes & 52 & 29 & 39 & 72 & 86 & 75 & 100 & 89 & 87 \\
\hline
\end{tabular}

* Expected value calculated as (Mean gene length $\times$ Number of genes)/sequenced genome size.

** Expected value calculated as 1 - exp[-average number of AFLPs within genes].

about 5 times larger than the average gene length for the species; Table 1) implying that about $2 \%$ of AFLP fragments could be located within $1 \mathrm{~kb}$ of the candidate genes, and $80 \%$ of the candidate genes would have possible markers within a $1 \mathrm{~kb}$ distance. However, these figures are substantially lower for the other examples, which give gene lengths of more average size (about $3.4 \mathrm{~kb}$; somewhat above the mean gene lengths for the species; see Table 1). Thus, only 1 or 2 AFLP fragments out of 1000 would be expected to be within a $1 \mathrm{~kb}$ distance from any of the candidate genes in the Aluminium tolerance or flowering time examples in Oryza and Arabidopsis, respectively; and only about $50 \%$ of the candidate genes would have possible markers at a $1 \mathrm{~kb}$ distance from them.

\section{Discussion}

AFLP markers are considered to be widely distributed across the genome [3] and thus to be useful markers for genome-wide scan studies for a variety of objectives, such as gene mapping, detection of signatures of selection and hybridization and introgression. However, it is well-known that the genomic sequences of many organisms display internal heterogeneities of different kinds, including variation in GC content, coding versus non coding sequences, hierarchies of repeats, etc. [47]. In fact, the distribution of AFLP fragments significantly deviates from that expected at random (e.g. [48-51]). Using in-silico analyses of different species it has been shown that the internal compositional heterogeneity of the genomes is responsible for the non-random physical distribution of AFLP markers [23].

The observation that many AFLP markers cluster around centromeric regions in genetic maps, as reported in Arabidopsis [37,39], potato, [48], soybean [50,51], wild emmer wheat [38], pink salmon [49], etc. is of particular interest. However, because this clustering has been observed in genetic maps, it was not possible to ascribe it only to a reduced recombination rate in these regions (e.g. $[50,51])$ or to a higher frequency of markers. In an important study addressing this issue, Peters et al. [39] carried out a combination of in-silico restriction fragment analysis and experimental AFLP analysis in Arabidopsis thaliana using SacI/MseI enzymes. They were able to 

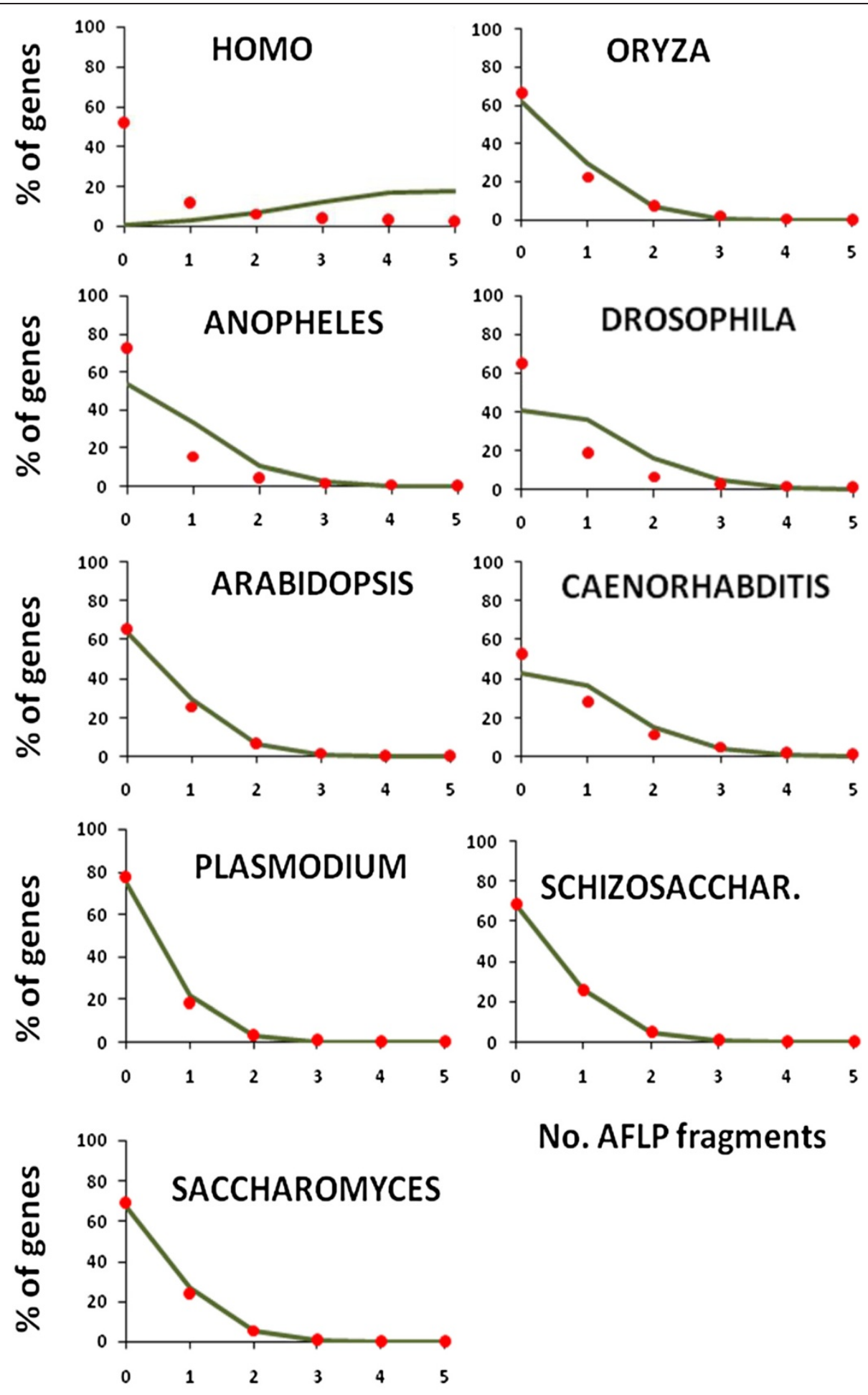

No. AFLP fragments

\section{No. AFLP fragments}

Figure 4 Distribution of the observed percentage of genes (red dots) with a given number of AFLP fragments (EcoRI/Msel) within their sequence. The line gives the expectation under a Poisson distribution. 
Table 2 In-silico analysis of candidate genes for Aluminium tolerance (AL) in Oryza sativa, developmental time (DT) in Drosophila melanogaster, and flowering time (FT) in Arabidopsis thaliana

\begin{tabular}{|c|c|c|c|}
\hline & $\begin{array}{l}\text { Oryza } \\
(A L)\end{array}$ & $\begin{array}{l}\text { Droso } \\
\text { (DT) }\end{array}$ & $\begin{array}{l}\text { Arab } \\
\text { (FT) }\end{array}$ \\
\hline Number of candidate genes & 42 & 89 & 50 \\
\hline Mean (stand. dev.) gene length (kb) & $3.4(2.0)$ & $30.4(30.2)$ & $3.4(1.8)$ \\
\hline \multicolumn{4}{|l|}{$\begin{array}{l}\% \text { AFLPs at a given distance from } \\
\text { genes }\end{array}$} \\
\hline $0 \mathrm{~kb}\left(\operatorname{EXP}^{*}\right)$ & $0.06(0.04)$ & $1.89(2.05)$ & $\begin{array}{l}0.14 \\
(0.14)\end{array}$ \\
\hline $1 \mathrm{~kb}$ & 0.09 & 2.02 & 0.24 \\
\hline 10 kb & 0.30 & 3.32 & 0.95 \\
\hline $100 \mathrm{~kb}$ & 2.39 & 14.73 & 7.51 \\
\hline \multicolumn{4}{|l|}{$\begin{array}{l}\% \text { Genes with AFLPs at a given } \\
\text { distance }\end{array}$} \\
\hline $0 \mathrm{~kb}\left(E X P^{* *}\right)$ & $43(50)$ & $73(99)$ & $34(47)$ \\
\hline $1 \mathrm{~kb}$ & 57 & 80 & 55 \\
\hline $10 \mathrm{~kb}$ & 86 & 99 & 98 \\
\hline $100 \mathrm{~kb}$ & 100 & 100 & 100 \\
\hline
\end{tabular}

* Expected value calculated as (Mean gene length $\times$ Number of candidate genes)/sequenced genome size.

** Expected value calculated as 1 - exp[-average number of AFLPs within candidate genes].

find the physical position of 1267 experimental AFLP markers in the genome, showing that $98.6 \%$ of the genome is covered by AFLPs. They showed that a reduced recombination rate in (peri) centromeric regions was only part of the explanation for the observed accumulation of AFLPs in these regions. In physical maps, there was still some agglomeration of empirical AFLP markers around centromeric regions. Nevertheless, Peters et al. [39] indicated that the occurrence of in-silico AFLP fragments was not increased in the (peri) centromeric regions, although this observation was not explicitly shown in the article. Here we have revisited the point regarding the typical enzyme system EcoRI/MseI and found an increase in the number of AFLP markers in the (peri) centromeric regions of some chromosomes, particularly chromosomes 3 and 5 (Figure 1A). This was shown to be both a consequence of the higher GC content in these regions (Figure $1 \mathrm{~B}$ and 2) and the presence of some repeated sequences which generate the same fragments. When AFLP bands rather than fragments are considered, which is more appropriate for an experimental setting, the (peri) centromeric agglomerations of AFLP markers mostly disappear (Figure 3). Thus, AFLP markers do not particularly accumulate in some regions of the genome. However, in experimental analyses, they still appear somewhat more frequently in the (peri) centromeric regions. Peters et al. [39] suggested that the explanation for this empirical observation may be that the frequency of mutations is increased in these regions. This is in fact a highly reasonable explanation, as it may be expected that the degree of polymorphism is larger in (peri) centromeric regions than in other coding sequences, so that segregating AFLP markers are more likely to be found in the former. In summary, the observed accumulation of empirical AFLP markers in (peri) centromeric regions can be due to a reduced recombination rate (for genetic maps; e.g. [50,51]) and a higher polymorphism (for genetic and physical maps [39]) in these regions. However, the physical distribution of AFLP markers, although non-random (e.g. [23,24]) has a coverage wide enough so as to become useful markers in genome-scan studies.

Regarding the location of AFLP markers relative to gene positions, we have shown that for the EcoRI/MseI system the percentage of AFLP markers located within gene sequences ranges between $28 \%$ and $87 \%$ depending on the species and it is somewhat larger than expected by chance. The reason is likely to be that the GC content for gene sequences is generally larger than for intergene sequences (e.g. $[43,44,52])$, and this increases the likelihood of enzyme cuts in the former. The use of enzymes with a higher GC content (BseI/TaqI and SacI/HpaII) further increases this likelihood. It is remarkable that, for example, using the pair SacI/HpaII in Arabidopsis, 86\% of the 6579 possible AFLP fragments are located within gene sequences, rising to $95 \%$ for fragments located within $1 \mathrm{~kb}$ distance from genes. These results are in agreement with those of Arnold et al. [21] in their analysis of the biases associated with RAD markers for the estimation of diversity. In their study, in silico digestion of D. melanogaster genomes indicated that GC-rich recognition sequences appear more frequently in exons, whereas AT-rich recognition sequences appear disproportionately more in intronic and intergenic regions. Therefore, we can conclude that using enzymes with high GC content could be more appropriate than enzymes with low GC content if the objective is to get available markers as close as possible to gene sequences.

The number of AFLP fragments clearly depends on the genome size, showing a rather linear relationship. The regression of the number of AFLP markers (EcoRI/MseI) on genome size for the nine species analysed has a slope of 152 markers per megabase with a squared correlation of $R^{2}=0.998$. If the human genome is excluded in the analysis, the slope is a bit lower, 125 markers per megabase, with $R^{2}=0.900$. Thus, the density of AFLP markers is of about one AFLP per $7 \mathrm{~kb}$. Using the enzymes BsmI/TaqI and SacI/HpaII, the corresponding slopes (including all 9 species) are $31\left(R^{2}=0.908\right)$ and $43\left(R^{2}=0.953\right)$ markers per megabase, respectively, implying densities of about one AFLP per $32 \mathrm{~kb}$ for BsmI/ 
TaqI and about one AFLP per $23 \mathrm{~kb}$ for SacI/HpaII. The corresponding densities in the genetic map vary substantially among species. For example, in Oryza and Arabidopsis $1 \mathrm{cM}$ corresponds to about $200-250 \mathrm{~kb}$ on average [39,53]. Thus, with EcoRI/MseI it is expected to be about 30 AFLPs per centimorgan for these species. However, in Drosophila $1 \mathrm{cM}$ corresponds to about $0.63 \mathrm{Mb}$ of sequence on average, and in Humans 0.82 Mb [54]. Thus, in these cases, there is an expected number of about 100 AFLPs per centimorgan. In general, therefore, the density of AFLP markers is relatively high, making AFLP markers generally suitable for genome scans.

When specific traits are considered, however, the percentage of AFLP markers within gene sequences or close to them can be rather small. We have illustrated this with some examples in three of the species analysed (Table 2). The results show that, for a typical trait controlled by a few dozen of genes of the typical gene size in the species, the number of AFLPs within $1 \mathrm{~kb}$ distance from those genes can be of the order of 1-2 in an AFLP analysis involving 1000 markers. In addition, only about $50 \%$ of the genes of interest would have markers within that distance. Thus, genome scans directed towards the search of markers closely associated to specific selected loci can be difficult depending on the situations. For example, genomic scans using molecular markers, such as AFLPs, are frequently used to infer adaptive population divergence [55-57]. Some of the methods used are based on the comparison between the observed levels of differentiation in gene frequencies among subpopulations with those expected under a neutral model of variation [58], with the objective of identifying those markers (outliers) that deviate significantly from the neutral expectation (see, e.g. $[56,59,60]$ ). It is generally assumed that local selection is extended over very small chromosomal regions $[61,62]$, and recent studies suggest that genetic differentiation of markers attached to local adaptation genes does not extend beyond about 1-5 kb around the adaptive loci $[45,63,64]$. In this situation, the probability of finding markers closely associated with selective loci must be really low even in analyses involving thousands of markers. However, regions of increased differentiation (islands of differentiation; [45]) through "divergence hitchhiking" [65], in which strong divergent selection between diverging populations reduces gene exchange, can reach several megabases sequence size $[65,66]$, and markers such as AFLPs can be appropriate to delineate these regions. In fact, analysis combining QTL mapping and detection of selective loci using AFLP markers show that the distance between the outlier markers and the nearest selected loci ranges 10-32 cM [65,67], which would imply physical distances in the order of megabases. In addition, computer simulations investigating the performance of methods in detecting selective loci under divergent selection with markers such as AFLPs shows that, despite the methods having substantial uncertainty, the average distance between detected outlier markers and true selective loci ranges between 7 and $18 \mathrm{cM}$ [68], in agreement with empirical observations.

\section{Conclusions}

In-silico AFLP analyses assessing the distribution of AFLP markers across the genomes of nine eukaryotic species indicates that AFLP bands do not particularly accumulate around (peri) centromeric regions. The percentage of AFLP markers positioned within gene sequences is usually larger than that expected by chance because of their higher GC content relative to intergene sequences. In fact, the use of enzyme pairs recognizing restriction sites with a larger GC content substantially increases the above percentages. Thus, enzymes with high GC content recognition sites should be used if the interest is to obtain markers within or close to gene sequences. The high coverage of AFLP markers across the genomes and the high proportion of markers within or close to gene sequences make them suitable for genome scanning and identifying large islands of genomic differentiation. However, their use in the search for markers closely linked to selected loci for specific traits can be a difficult task, as only a small percentage of markers are expected to be close to particular genes of interest.

\section{Methods}

Whole genome sequences and data on gene positions on the genome were obtained from 9 eukaryotic species (Homo sapiens, Oryza sativa, Anopheles gambiae, Drosophila melanogaster, Arabidopsis thaliana, Caenohabditis elegans, Plasmodium falciparum, Saccharomyces cerevisiae and Schizosaccharomyces pombe) obtained from the NCBI Entrez Genome database. These species were chosen because of their high coverage of genome sequencing, their assignment of all sequences to chromosomal locations, and because they cover a wide spectrum of genome sizes. A computer program written in C [23] was used to simulate the cutting of the whole genome with two restriction enzymes so as to produce AFLP fragments. We mainly considered the typical enzymes used in AFLP studies, EcoRI and MseI (cutting at sites GAATTC and TTAA, respectively), but analyses were also carried out with restriction enzymes with a balanced AT/GC recognition sequence (BsmI and TaqI, with sites GAATGC and TCGA, respectively) and with a biased GC composition ( $\mathrm{SacI}$ and HpaII, with sites GAGCTC and CCGG, respectively). Only fragments EcoRI-MseI, BsmI-TaqI or SacI-HpaII with sizes between 40 and 440 nucleotides (which correspond to PCR fragments between 72 and 472 when the typical primers are added) were used to mimic the experimental 
procedure used in AFLP studies. The distance in basepairs between consecutive AFLP fragments and between each AFLP fragment and its closest gene were recorded.

In order to illustrate the number of AFLP markers closest to specific sets of genes, three examples of candidate loci were analysed. These correspond to 46 candidate genes for Aluminium tolerance in Oryza sativa [53], 51 candidate genes for flowering time in Arabidopsis thaliana [69], and 102 candidate genes for developmental time in Drosophila melanogaster [70]. The locations of these candidate genes were searched for in the GENBANK (Drosophila and Arabidopsis) and PLANTPAN (Oryza) databases, but only 42, 50 and 89 genes (respectively) were localised and considered in the analysis.

\section{Additional file}

Additional file 1: Distribution of the number of AFLP bands (EcoRI/ Msel) (in red) and the number of genes (in blue) across the different species, shown in non-overlapping windows of 100 or $200 \mathrm{~kb}$. (S1) Homo sapiens (regions with no markers and genes denote unsequenced genomic areas). (S2) Oryza sativa (regions with no markers and genes denote unsequenced genomic areas). (S3) Anopheles gambiae. (S4) Drosophila melanogaster. (S5) Caenorhabditis elegans. (S6) Plasmodium falciparum. (S7) Schizosaccharomyces pombe. (S8) Saccharomyces cerevisiae.

\section{Competing interests}

The authors declare they have no competing interests.

\section{Authors' contributions}

All authors contributed to the design of the study and the writing of the manuscript. AC and MJGP carried out the computer analyses. All authors read and approved the final manuscript.

\section{Authors' information}

The authors are members of the Population Genetics and Cytogenetics Group of the University of Vigo (http://webs.uvigo.es/genxb2/).

\section{Acknowledgements}

We thank Raquel Sampedro for technical assistance, Mark P. Simmons for useful comments on the manuscript, and Ramón Fallon for English corrections. This work was funded by the Ministerio de Economía y Competitividad (CGL2012-39861-C02), the Xunta de Galicia (10PXIB 310044PR, Grupos de Referencia Competitiva, 2010/80) and Fondos Feder: "Unha maneira de facer Europa".

Received: 18 April 2013 Accepted: 30 July 2013

Published: 1 August 2013

\section{References}

1. Vos P, Hogers R, Bleeker M, Reijans M, van de Lee T, Hornes M, Frijters A, Pot J, Peleman J, Kuiper M: AFLP: a new technique for DNA fingerprinting. Nucleic Acids Res 1995, 23(21):4407-4414.

2. Bonin A, Ehrich D, Manel S: Statistical analysis of amplified fragment length polymorphism data: a toolbox for molecular ecologists and evolutionists. Mol Ecol 2007, 16(18):3737-3758.

3. Meudt HM, Clarke AC: Almost forgotten or latest practice? AFLP applications, analyses and advances. Trends Plant Sci 2007, 12(3):106-117.

4. Bensch S, Akesson M: Ten years of AFLP in ecology and evolution: why so few animals? Mol Ecol 2005, 14(10):2899-2914.

5. Peters JL, Cnops G, Neyt P, Zethof J, Cornelis K, Van Lijsebettens M, Gerats T: An AFLP-based genome-wide mapping strategy. Theor Appl Genet 2004, 108(2):321-327.
6. Gosset CC, Bierne N: Differential introgression from a sister species explains high F(ST) outlier loci within a mussel species. J Evol Biol 2013, 26(1):14-26.

7. Ley AC, Hardy OJ: Improving AFLP analysis of large-scale patterns of genetic variation - a case study with the Central African lianas Haumania spp (Marantaceae) showing interspecific gene flow. Mol Ecol 2013, 22(7):1984-1997.

8. Hoffman J, Clark M, Amos W, Peck L: Widespread amplification of amplified fragment length polymorphisms (AFLPs) in marine Antarctic animals. Polar Biol 2012, 35(6):919-929.

9. Després L, Gielly L, Redoutet B, Taberlet P: Using AFLP to resolve phylogenetic relationships in a morphologically diversified plant species complex when nuclear and chloroplast sequences fail to reveal variability. Mol Phylogenet Evol 2003, 27(2):185-196.

10. Koopman WJ: Phylogenetic signal in AFLP data sets. Syst Biol 2005 54(2):197-217.

11. Luo R, Hipp AL, Larget B: A Bayesian model of AFLP marker evolution and phylogenetic inference. Stat Appl Genet Mol Biol 2007, 6(1):11. Article 11.

12. Wilding C, Butlin R, Grahame J: Differential gene exchange between parapatric morphs of Littorina saxatilis detected using AFLP markers. $J$ Evol Biol 2001, 14(4):611-619.

13. Bonin A, Taberlet P, Miaud C, Pompanon F: Explorative genome scan to detect candidate loci for adaptation along a gradient of altitude in the common frog (Rana temporaria). Mol Biol Evol 2006, 23(4):773-783.

14. Paris $M$, Despres $L$ : Identifying insecticide resistance genes in mosquito by combining AFLP genome scans and 454 pyrosequencing. Mol Ecol 2012, 21(7):1672-1686.

15. Galindo J, Morán P, Rolán-Alvarez E: Comparing geographical genetic differentiation between candidate and noncandidate loci for adaptation strengthens support for parallel ecological divergence in the marine snail Littorina saxatilis. Mol Ecol 2009, 18(5):919-930.

16. Paris M, Boyer S, Bonin A, Collado A, David JP, Despres L: Genome scan in the mosquito Aedes rusticus: population structure and detection of positive selection after insecticide treatment. Mol Ecol 2010, 19(2):325-337.

17. Tice KA, Carlon DB: Can AFLP genome scans detect small islands of differentiation? The case of shell sculpture variation in the periwinkle Echinolittorina hawaiiensis. J Evol Biol 2011, 24(8):1814-1825.

18. Miller MR, Dunham JP, Amores A, Cresko WA, Johnson EA: Rapid and cost-effective polymorphism identification and genotyping using restriction site associated DNA (RAD) markers. Genome Res 2007, 17(2):240-248

19. Rowe $H C$, Renaut $S$, Guggisberg $A: R A D$ in the realm of next-generation sequencing technologies. Mol Ecol 2011, 20(17):3499-3502.

20. Gautier M, Gharbi K, Cezard T, Foucaud J, Kerdelhué C, Pudlo P, Cornuet JM, Estoup A: The effect of RAD allele dropout on the estimation of genetic variation within and between populations. Mol Ecol 2012, 22(11):3165-3178.

21. Arnold B, Corbett-Detig RB, Hartl D, Bomblies K: RADseq underestimates diversity and introduces genealogical biases due to nonrandom haplotype sampling. Mol Ecol 2013, 22(11):3179-3190.

22. Vekemans $X$, Beauwens $T$, Lemaire $M$, Roldán-Ruiz I: Data from amplified fragment length polymorphism (AFLP) markers show indication of size homoplasy and of a relationship between degree of homoplasy and fragment size. Mol Ecol 2002, 11(1):139-151.

23. Caballero A, Quesada H: Homoplasy and distribution of AFLP fragments: an analysis in silico of the genome of different species. Mol Biol Evol 2010, 27(5):1139-1151.

24. Koopman WJ, Gort G: Significance tests and weighted values for AFLP similarities, based on Arabidopsis in silico AFLP fragment length distributions. Genetics 2004, 167(4):1915-1928

25. Gort G, Koopman WJ, Stein A: Fragment length distributions and collision probabilities for AFLP markers. Biometrics 2006, 62(4):1107-1115.

26. Caballero A, Quesada $H$, Rolán-Alvarez E: Impact of amplified fragment length polymorphism size homoplasy on the estimation of population genetic diversity and the detection of selective loci. Genetics 2008, 179(1):539-554.

27. Simmons MP, Zhang $L B$, Webb $C T$, Müller $K$ : A penalty of using anonymous dominant markers (AFLPs, ISSRs, and RAPDs) for phylogenetic inference. Mol Phylogenet Evol 2007, 42(2):528-542.

28. García-Pereira MJ, Caballero A, Quesada H: Evaluating the relationship between evolutionary divergence and phylogenetic accuracy in AFLP data sets. Mol Biol Evol 2010, 27(5):988-1000. 
29. García-Pereira MJ, Caballero A, Quesada H: The relative contribution of band number to phylogenetic accuracy in AFLP data sets. J Evol Biol 2011, 24(11):2346-2356.

30. García-Pereira MJ, Quesada H, Caballero A, Carvajal-Rodríguez A: AFLPMax: a user-friendly application for computing the optimal number of amplified fragment length polymorphism markers needed in phylogenetic reconstruction. Mol Ecol Resour 2012, 12(3):566-569.

31. Gort G, van Hintum $T$, van Eeuwijk F: Homoplasy corrected estimation of genetic similarity from AFLP bands, and the effect of the number of bands on the precision of estimation. Theor App/ Genet 2009, 119(3):397-416.

32. Nunes VL, Beaumont MA, Butlin RK, Paulo OS: Challenges and pitfalls in the characterization of anonymous outlier AFLP markers in non-model species: lessons from an ocellated lizard genome scan. Heredity (Edinb) 2012, 109(6):340-348.

33. Pompanon F, Bonin A, Bellemain E, Taberlet P: Genotyping errors: causes, consequences and solutions. Nat Rev Genet 2005, 6(11):847-859.

34. Holland BR, Clarke AC, Meudt HM: Optimizing automated AFLP scoring parameters to improve phylogenetic resolution. Syst Biol 2008, 57(3):347-366

35. Whitlock R, Hipperson H, Mannarelli M, Butlin RK, Burke T: An objective, rapid and reproducible method for scoring AFLP peak-height data that minimizes genotyping error. Mol Ecol Resour 2008, 8(4):725-735.

36. Kück P, Greve C, Misof B, Gimnich F: Automated masking of AFLP markers improves reliability of phylogenetic analyses. PLoS One 2012, 7(11):e49119.

37. Alonso-Blanco C, Peeters AJ, Koornneef M, Lister C, Dean C, van den Bosch N, Pot J, Kuiper MT: Development of an AFLP based linkage map of Ler, Col and Cvi Arabidopsis thaliana ecotypes and construction of a Ler/Cvi recombinant inbred line population. Plant J 1998, 14(2):259-271.

38. Peng J, Korol AB, Fahima T, Röder MS, Ronin YI, Li YC, Nevo E: Molecular genetic maps in wild emmer wheat, Triticum dicoccoides: genome-wide coverage, massive negative interference, and putative quasi-linkage. Genome Res 2000, 10(10):1509-1531.

39. Peters JL, Constandt H, Neyt P, Cnops G, Zethof J, Zabeau M, Gerats T: A physical amplified fragment-length polymorphism map of Arabidopsis. Plant Physiol 2001, 127(4):1579-1589.

40. Karlin S, Burge C: Dinucleotide relative abundance extremes: a genomic signature. Trends Genet 1995, 11(7):283-290.

41. Jernigan RW, Baran $\mathrm{RH}$ : Pervasive properties of the genomic signature. BMC Genomics 2002, 3(1):23.

42. Wang $Y$, Hill K, Singh S, Kari L: The spectrum of genomic signatures: from dinucleotides to chaos game representation. Gene 2005, 346:173-185.

43. Bernardi G, Olofsson B, Filipski J, Zerial M, Salinas J, Cuny G, Meunier-Rotival $\mathrm{M}$, Rodier F: The mosaic genome of warm-blooded vertebrates. Science 1985, 228(4702):953-958.

44. Zoubak S, Clay O, Bernardi G: The gene distribution of the human genome. Gene 1996, 174(1):95-102.

45. Turner TL, Bourne EC, Von Wettberg EJ, Hu TT, Nuzhdin SV: Population resequencing reveals local adaptation of Arabidopsis lyrata to serpentine soils. Nat Genet 2010, 42(3):260-263.

46. Initiative AG: Analysis of the genome sequence of the flowering plant Arabidopsis thaliana. Nature 2000, 408(6814):796-815.

47. Karlin S, Mrázek J, Campbell AM: Compositional biases of bacterial genomes and evolutionary implications. J Bacterio/ 1997, 179(12):3899-3913.

48. Vaneck H, Vanddervoort J, Draaistra J, Vanzandvoort P, Vanenckevorte $E$, Segers B, Peleman J, Jacobsen E, Helder J, Bakker J: The Inheritance and chromosomal localization of AFLP markers in a noninbred potato offspring. Mol Breed 1995, 1(4):397-410.

49. Lindner KR, Seeb JE, Habicht C, Knudsen KL, Kretschmer E, Reedy DJ, Spruell $P$, Allendorf FW: Gene-centromere mapping of 312 loci in pink salmon by half-tetrad analysis. Genome 2000, 43(3):538-549.

50. Keim P, Schupp J, Travis S, Clayton K, Zhu T, Shi L, Ferreira A, Webb D: A high-density soybean genetic map based on AFLP markers. Crop Sci 1997, 37(2):537-543.

51. Young W, Schupp J, Keim P: DNA methylation and AFLP marker distribution in the soybean genome. Theor App/ Genet 1999, 99(5):785-792.

52. Jabbari K, Bernardi G: Comparative genomics of Anopheles gambiae and Drosophila melanogaster. Gene 2004, 333:183-186.

53. Famoso AN, Zhao K, Clark RT, Tung CW, Wright MH, Bustamante C, Kochian LV, McCouch SR: Genetic architecture of aluminum tolerance in rice (Oryza sativa) determined through genome-wide association analysis and QTL mapping. PLoS Genet 2011, 7(8):e1002221.
54. Beye M, Gattermeier I, Hasselmann M, Gempe T, Schioett M, Baines JF, Schlipalius D, Mougel F, Emore C, Rueppell O, et al: Exceptionally high levels of recombination across the honey bee genome. Genome Res 2006, 16(11):1339-1344.

55. Storz JF: Using genome scans of DNA polymorphism to infer adaptive population divergence. Mol Ecol 2005, 14(3):671-688.

56. Butlin RK: Population genomics and speciation. Genetica 2010, 138(4):409-418.

57. Nosil P, Feder JL: Genomic divergence during speciation: causes and consequences. Philos Trans R Soc Lond B Biol Sci 2012, 367(1587):332-342.

58. Lewontin RC, Krakauer J: Distribution of gene frequency as a test of the theory of the selective neutrality of polymorphisms. Genetics 1973, 74(1):175-195

59. Nosil P, Funk DJ, Ortiz-Barrientos D: Divergent selection and heterogeneous genomic divergence. Mol Ecol 2009, 18(3):375-402.

60. Pérez-Figueroa A, García-Pereira MJ, Saura M, Rolán-Alvarez E, Caballero A: Comparing three different methods to detect selective loci using dominant markers. J Evol Biol 2010, 23(10):2267-2276.

61. Charlesworth B, Nordborg M, Charlesworth D: The effects of local selection, balanced polymorphism and background selection on equilibrium patterns of genetic diversity in subdivided populations. Genet Res 1997, 70(2):155-174.

62. Feder $\mathrm{J}$, Nosil P: The efficacy of divergence hitchhiking in generating genomic islands during ecological speciation. Evolution 2010, 64(6):1729-1747.

63. Kolaczkowski B, Kern AD, Holloway AK, Begun DJ: Genomic differentiation between temperate and tropical Australian populations of Drosophila melanogaster. Genetics 2011, 187(1):245-260.

64. Bierne N, Welch J, Loire E, Bonhomme F, David P: The coupling hypothesis: why genome scans may fail to map local adaptation genes. Mol Ecol 2011, 20(10):2044-2072.

65. Via S: Divergence hitchhiking and the spread of genomic isolation during ecological speciation-with-gene-flow. Philos Trans $R$ Soc B - Biol Sci 2012, 367(1587):451-460

66. Renaut S, Maillet N, Normandeau E, Sauvage C, Derome N, Rogers SM, Bernatchez $L$ : Genome-wide patterns of divergence during speciation: the lake whitefish case study. Philos Trans R Soc Lond B Biol Sci 2012, 367 (1587):354-363.

67. Via S, West J: The genetic mosaic suggests a new role for hitchhiking in ecological speciation. Mol Ecol 2008, 17(19):4334-4345.

68. Vilas A, Pérez-Figueroa A, Caballero A: A simulation study on the performance of differentiation-based methods to detect selected loci using linked neutral markers. J Evol Biol 2012, 25(7):1364-1376.

69. Ehrenreich IM, Hanzawa Y, Chou L, Roe JL, Kover PX, Purugganan MD Candidate gene association mapping of Arabidopsis flowering time. Genetics 2009, 183(1):325-335.

70. Mensch J, Lavagnino N, Carreira VP, Massaldi A, Hasson E, Fanara JJ: Identifying candidate genes affecting developmental time in Drosophila melanogaster: pervasive pleiotropy and gene-by-environment interaction. BMC Dev Biol 2008, 8:78.

doi:10.1186/1471-2164-14-528

Cite this article as: Caballero et al:: Genomic distribution of AFLP markers relative to gene locations for different eukaryotic species. BMC Genomics 2013 14:528.

\section{Submit your next manuscript to BioMed Central and take full advantage of:}

- Convenient online submission

- Thorough peer review

- No space constraints or color figure charges

- Immediate publication on acceptance

- Inclusion in PubMed, CAS, Scopus and Google Scholar

- Research which is freely available for redistribution 